\title{
AVAliação das PERdas físicas de UM SETOR DA REDE DE abastecimento de Água de Campo Grande-MS VIA MODELO INVERSO
}

\section{Leakage eVAluation in A WATER SUPply NeTWORK SECTOR OF CAMPO GRANDE-MS THROUGH INVERSE MODEL}

\author{
ALEXANDRE KEPLER SOARES \\ Engenheiro Civil - Universidade Federal de Mato Grosso do Sul - UFMS \\ Mestre e Doutorando em Hidráulica e Saneamento - EESC/USP
}

\section{Peter Batista Cheung}

Engenheiro Civil - Universidade Federal de Mato Grosso do Sul - UFMS. Mestre em Tecnologias Ambientais - UFMS Doutor em Hidráulica e Saneamento - EESC/USP. Pós-Doutorando em Hidráulica - CEMAGREF/Bordeaux, França

\section{LUISA FERNANDA RIBEIRO REIS}

Engenheira Civil - Universidade de Campinas - UNICAMP. Mestre e Doutora em Hidráulica e Saneamento - EESC/USP. Professora Associada do Departamento de Hidráulica e Saneamento da EESC/USP

\section{Marilúcta Pereira SANDim}

Engenheira Civil - Universidade Federal de Mato Grosso do Sul - UFMS. Mestranda em Tecnologias Ambientais - UFMS. Gerente de Projetos da Empresa de Saneamento Águas Guariroba S. A., Campo Grande-MS

Recebido: 26/03/04 Aceito: 30/07/04

\section{RESUMO}

O crescimento do contingente populacional das cidades requer o gerenciamento eficiente dos recursos hídricos, particularmente quando a exploração de novas fontes de abastecimento mostrase dispendiosa e os recursos naturais cada vez mais escassos. Em contrapartida, em diversas cidades brasileiras, são comuns redes de distribuição de água para abastecimento com elevados índices de perdas, sejam elas não-físicas ou físicas (perdas por vazamento). O presente estudo visa avaliar as perdas por vazamentos de um setor da rede de distribuição de água da cidade de Campo Grande-MS. Para tanto, utiliza-se um procedimento iterativo de avaliação hidráulica que considera as perdas por vazamento e a dependência das demandas com a pressão, utilizando o simulador hidráulico EPANET 2 (Rossman, 2000), com vistas à calibração em termos dos parâmetros do modelo de vazamentos, bem como dos coeficientes de perda de carga localizada relativa a componentes hidráulicos presentes na rede. Para a resolução do problema inverso correspondente são utilizados os Algoritmos Genéticos (AGs).

PALAVRAS-CHAVE: Perdas por vazamento, calibração, redes de distribuição de água reais.

\section{ABSTRACT}

The increasing population of the cities requires an efficient water resources management, particularly when new supply source explorations are costly and natural resources are growing scarce. On the other hand, in several Brazilian cities, water distribution networks usually present a high percentage of water losses due to nonphysical or physical losses (leakage). The present study seeks to evaluate the leakage of a water distribution network sector in the city of Campo Grande-MS. An iterative procedure for hydraulic analysis based both on leakage and on pressure-dependent demand has been used in conjunction with the hydraulic simulator EPANET 2 (Rossman, 2000). The calibration is conducted in terms of the parameters of the leakage model, as well as the head loss coefficients due to hydraulic components in the network. Genetic Algorithms (GAs) have been used to solve the corresponding inverse problem.

KEYWORDS: Leakage losses, calibration, existing water distribution networks.

\section{INTRODUÇÃO}

Considerando que não existem sistemas estanques, toda rede de abastecimento de água existente apresenta alguma parcela de perdas por vazamento na distribuiçãao. A quantificação dos vazamentos distribuídos ao longo da rede pode ser feita por meio da inclusão de modelos pressão $\mathrm{x}$ vazamento nas análises hidráulicas. Entretanto, para que esses modelos possam realizar estimativas confiáveis, é necessário, primeiramente, que seus parâmetros sejam conhecidos. Além disso, é necessário que as relações entre pressão e demanda sejam consideradas.

A calibração de um modelo de rede de distribuiçãao de água é um procedi- 
mento preliminar a ser adotado antes de qualquer análise de reabilitação e/ou operação de sistemas existentes com o objetivo de identificar os seus parâmetros e assim poder avaliar, por meio de simulaçóes hidráulicas, o comportamento mais realístico das suas variáveis de estado (pressão, vazão). A calibração visa o ajuste dos parâmetros do sistema de tal forma que os desvios entre os dados simulados e observados em campo sejam minimizados.

O procedimento geral para calibração de um modelo de rede pode ser dividido em seis etapas:

1. Obtenção de dados cadastrais (consulta de informaçôes) referentes às características físicas das tubulações (diâmetros, rugosidades, comprimento e material) e características dos componentes (válvulas e bombas), elevações topográficas, consumos das quadras, incidência de vazamentos, dentre outros;

2. Simplificação da rede, desconsiderando diâmetros inferiores a $150 \mathrm{~mm}$, salvo algumas exceções (ponta de rede, proximidades de reservatórios, mudança de diâmetro, dentre outras);

3. Divisão da rede em setores homogêneos em termos das rugosidades e parâmetros do modelo de vazamentos, de forma que as estimativas para cada setor de rede correspondam a um fator de ajuste global para esse setor;

4. Detecção e reparo de vazamentos via campanhas de geofonamento;

5. Instalação de medidores de pressão e vazão (medidas preliminares de campo) na rede, de forma a armazenar tais dados simultaneamente com as informaçōes relativas aos níveis dos reservatórios;

6. Simulação da rede (análises via computador) utilizando os dados coletados para obter valores das variáveis de estado (pressão e vazão) e compará-los (modelo de calibração) com os dados obtidos em campo. Se o ajuste é aceitável, a calibração é finalizada, caso contrário, volta-se à etapa de simulação, determinando (por algum processo de otimização) novos valores para os parâmetros e assim por diante, até que o critério de convergência seja satisfeito.

No presente trabalho, foram identificados os parâmetros do modelo pressão $\mathrm{x}$ vazamento para um setor da rede de distribuição de água da cidade de Campo Grande-MS. Para tanto, utilizaram-se modelos inversos, resolvidos com o suporte da tecnologia dos Algoritmos Genéticos (AGs), alimentados por dados obtidos em campo.

Os valores de pressão em alguns nós da rede e da vazão abastecida coletados são os dados necessários para a determinação dos parâmetros do modelo pressão $\mathrm{x}$ vazamento.

As simulaçōes hidráulicas realizadas neste trabalho utilizaram o simulador hidráulico proposto por Soares (2003), no qual tanto as perdas por vazamento quanto a dependência das demandas com a pressão são considerados simultaneamente. $\mathrm{O}$ procedimento iterativo utiliza o simulador EPANET 2 (Rossman, 2000) como módulo auxiliar nas análises hidráulicas, pois as rotinas de cálculo das perdas por vazamento e de avaliação das demandas dependentes da pressão foram implementadas (em linguagem $\mathrm{C}++$ ) externamente ao referido simulador hidráulico.

\section{MODELO INVERSO}

O problema de calibração resolvido foi expresso como de minimização dos desvios entre os valores de pressão e vazão, observados e simulados hidraulicamente, segundo a equação:

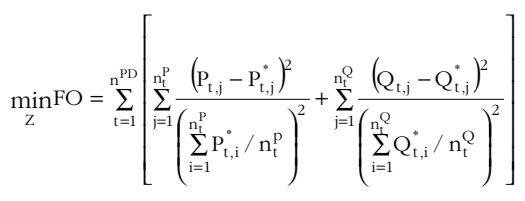

sendo $\mathrm{n}^{\mathrm{PD}} \mathrm{o}$ número de padrões de demanda observados, $\mathrm{n}_{\mathrm{t}}{ }^{\mathrm{P}} \mathrm{o}$ número de observações de pressões realizadas para $o$ padrão $t, n_{t}{ }^{Q} \mathrm{o}$ número de observações de vazôes realizadas para o padrão t, $P$ as pressões simuladas, $\mathrm{P}^{*}$ as pressões observadas, $\mathrm{Q}$ as vazões simuladas, $\mathrm{Q}^{*}$ as vazões observadas e $Z$ o conjunto de todas as variáveis de decisão do problema, dado por:

$$
\mathrm{Z}=\left(\theta_{1}, \ldots, \theta_{\mathrm{n}_{\theta}}, \beta_{1}, \ldots, \beta_{\mathrm{n}_{\beta}}, \mathrm{K}_{1}, \ldots, \mathrm{K}_{\mathrm{n}_{\mathrm{T}}}\right)
$$

sendo $\theta$ o coeficiente de perda do modelo de vazamentos, b o expoente de perda do modelo de vazamentos, Ko coeficiente de perda de carga localizada devido à presença de singularidades nas tubulaçóes (registros, válvulas ou tubos incrustados), $\mathrm{n}_{\mathrm{T}}$ o número de singularidades supostamente presentes na rede, $n_{\theta}$ e $n_{\beta} O$ número de setores com coeficiente e expoente de vazamento homogêneos, respectivamente. A consideração de setores com variáveis de decisão homogêneas é uma sistemática que visa a redução do grau de parametrização do problema e, por conseqüência, do grau de indeterminação da solução. Assim, ao in- vés da determinação de parâmetros para cada tubulação e nó, são considerados setores com valores homogêneos dos parâmetros a serem estimados.

Neste trabalho, foram considerados dois padrões de demanda, correspondentes às condiçôes de vazão abastecida máxima (horas do dia em que o consumo é maior, portanto com menores níveis de vazamentos e maiores restrições na vazão de atendimento da demanda potencial devido às menores pressões na rede) e mínima (horas do dia em que o consumo é menor ou quase nulo, com maiores índices de vazamentos e menor ou nenhuma restrição na vazão de atendimento da demanda potencial devido aos maiores níveis de pressão).

Para a resolução do problema inverso definido pela Equação 1, são utilizados os Algoritmos Genéticos (AGs), tipo geracional elitista, com o emprego da biblioteca GAlib C++ (Wall, 1996), de distribuição livre.

Para o cômputo de P e Q, respectivamente, pressões e vazões simuladas, é utilizado o simulador hidráulico proposto por Soares (2003), que implementa a formulação proposta por Tucciarelli et al. (1999) para a avaliação das perdas por vazamento distribuído ao longo da rede, de acordo com a seguinte equação:

$v_{i}=\left(H_{i}-z_{i}\right)^{\beta} \sum_{j=1}^{M_{i}} \frac{\pi}{2} D_{i j} \theta_{i j} L_{i j}$

sendo $\mathrm{H}_{\mathrm{i}}$ a carga hidráulica no nó $\mathrm{i}, \mathrm{z}_{\mathrm{i}} \mathrm{a}$ cota topográfica, $\beta$ o expoente de perda, $\mathrm{M}_{\mathrm{i}} \mathrm{o}$ número de tubulaçóes conectadas ao nó i, $\mathrm{D}_{\mathrm{ij}}$ o diâmetro da tubulação ligando os nós i e j, $\mathrm{L}_{\mathrm{ij}}$ o comprimento da tubulação e $\theta_{\mathrm{ij}}$ o coeficiente de perda por unidade de superfície do tubo ligando os nós i e j.

A relação entre a demanda efetivamente abastecida e a demanda potencial no nó i $\left(\rho_{i}\right)$, é especificada de acordo com o modelo pressão x demanda também proposto por Tucciarelli et al. (1999), dado por:

$\begin{array}{lll}\rho_{i}=1 & \text { se } & P_{i} \geq P_{i}^{\text {des }} \\ \rho_{i}=\operatorname{sen}^{2}\left(\frac{P_{i}}{2 \cdot P^{\text {des }}} \pi\right) & \text { se } & P_{i}^{\text {min }} \leq P_{i} \leq P_{i}^{\text {des }} \\ \rho_{i}=0 & \text { se } & P_{i} \leq P_{i}^{\text {min }}\end{array}$

sendo $\mathrm{P}_{\mathrm{i}}^{\text {des }}$ a pressão desejada para suprimento total da demanda potencial, $\mathrm{P}_{\mathrm{i}}^{\min }$ a pressão mínima abaixo da qual não há abastecimento $\mathrm{P}_{\mathrm{i}}$ a pressão atuante no nó i. Neste trabalho, foi adotado $\mathrm{P}^{\mathrm{min}}=0 \mathrm{e} \mathrm{P}^{\text {des }}=5 \mathrm{~m}$, embora se reconheça que a adoção de tais valores deva ser objeto de estudos mais detalhados. 


\section{DESCRICÃO DO SISTEMA EM ESTUDO}

O sistema de abastecimento de água da cidade de Campo Grande-MS, é dividido em 20 setores operacionais, responsáveis pelo atendimento de 706.442 habitantes (Sandim et al., 2002). Dentre eles, o sistema de distribuição RF-1/TH é o setor operacional que apresenta o maior índice de perdas físicas e não físicas, em média $48 \%$, e por isso, foi escolhido como objeto de estudo deste trabalho. Esse setor localiza-se na região norte do município de Campo Grande, sendo abastecido totalmente pelo sistema integrado (compreende as regióes da cidade cujo abastecimento tem como fontes de suprimento principais as captaçóes superficiais). Esse setor é divido em parte alta (TH) e parte baixa (RF-1) e, neste trabalho, apenas a parte baixa (setor RF-1) é investigada.

O suprimento de água do setor de distribuição RF-1 ocorre por meio de dois reservatórios semi-enterrados, cada qual com um volume de armazenamento de $6000 \mathrm{~m}^{3}$. Esse setor é responsável pelo atendimento de aproximadamente 100.000 habitantes (Sandim et al., 2002) sendo a sua rede composta por tubos de PVC, cimento amianto e ferro fundido, com uma extensão total de 54.530 metros (rede primária).

\section{Etapas da calibração}

Os procedimentos de calibração anteriormente citados foram desenvolvidos com exceção da quarta etapa, por razões de tempo e não disponibilidade de mão-de-obra para tal.

\section{Simplificação da rede}

Considerando que a rede de distribuiçãa do setor RF-1 é de grande porte, neste trabalho foram desprezadas tubulações com diâmetros inferiores a $150 \mathrm{~mm}$, salvo exceçóes como pontas de rede e mudanças de diâmetro, resultando em um modelo simplificado real com 130 nós e 146 tubulações, conforme ilustrado pela Figura 1. Os dados referentes às características físicas das tubulaçōes e aos componentes hidráulicos foram obtidos junto à Companhia de Saneamento Águas Guariroba S. A., que já possuía o cadastro da rede em forma de arquivo de dados para o software EPANET.

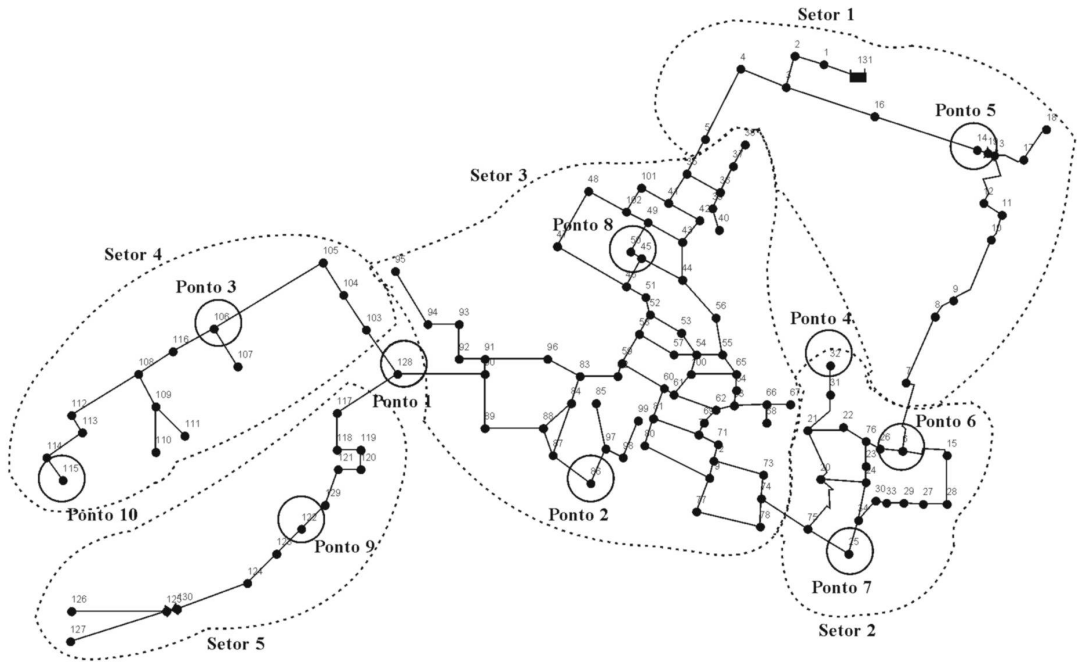

Figura I - Setores e pontos de amostragem de pressão na rede simplificada real

\section{Divisão da rede em setores}

Conforme o procedimento geral de calibração do modelo descrito anteriormente, divide-se a rede em setores homogêneos em termos das rugosidades e dos parâmetros do modelo de vazamentos. Neste trabalho, a rede foi divida em termos das áreas de incidências de vazamentos conforme mapa fornecido pela Companhia de Saneamento Águas Guariroba S.A.. A Figura 1 apresenta o modelo simplificado real divido em setores.

As demandas nos nós foram obtidas utilizando-se a base cadastral do ano de 1996 para realizar a projeção para o ano de 2003, utilizando índices de crescimento populacional apresentados no plano diretor do sistema de abastecimento de água (Sandim et al., 2002). Assim, os resultados do trabalho podem apresentar alguma imprecisão, pois, sendo os consumos estimados, os vazamentos calculados apresentam um erro associado. Isso demonstra a dificuldade de se obter dados de consumo dos sistemas de abastecimento e, principalmente, relacionálos com o cadastro da rede.

\section{Coleta de dados}

Dez medidores de pressão (Metrolog NA Data Logger da Technolog) foram utilizados para armazenar dados referentes às pressões atuantes na rede durante $o$ período de observação (10 a 23 de abril de 2003). Além disso, um computador portátil foi utilizado para extrair os dados armazenados em campo.

Em relação às medidas de vazão, foram utilizados dados da Central de Controle de Processos (CCP), que recebe informaçôes a cada minuto dos reservatórios e da vazão abastecida do setor RF-1 a cada minuto através de um sistema de telemetria. Para alimentar o sistema de telemetria, há um macromedidor eletromagnético instalado na saída do reservatório (dois reservatórios semi-enterrados funcionando como vasos comunicantes) e na entrada da rede de distribuiçãa do sistema RF-1.

Para a coleta de informaçôes simultâneas, promoveu-se a sincronização de leitura dos medidores de pressão e do macromedidor eletromagnético de vazão. Os medidores de pressão foram ajustados para registrar pressóes em intervalos consecutivos de 10 minutos. Esse ajuste, bem como a formatação dos dados, é feito pelo software (GP2) fornecido pelo fabricante dos medidores de pressão.

Para avaliar as vazóes mínimas noturnas (avaliação de vazamentos), foi solicitada junto à companhia a realização de manobras sobre o registro existente na entrada da rede (setor RF-1). Entretanto, foi alegado pela companhia que a manobra desse registro não seria possível devido a fatores nocivos tais como o possível comprometimento do abastecimento, entrada de ar na rede, ocorrência de transientes hidráulicos de elevada intensidade, dentre outros fatores. Além disso, foi solicitado que pelo menos um dia durante o período de coleta de dados não 
fossem realizadas manobras na rede para não interferir nos dados de pressão.

As tomadas de pressão foram realizadas em cavaletes residenciais e as diferenças existentes entre as cotas da rede e as cotas dos cavaletes residenciais foram desprezadas.

Os pontos de instalação (pontos de amostragem) dos medidores de pressão foram escolhidos conforme mapa de incidência de vazamentos fornecido pela companhia de saneamento e são apresentados na Figura 1.

Conforme mencionado, a investigação de campo foi realizada no período de 10 e 23 de abril de 2003. Entretanto, entre os dias 10 e 16 as investigações foram destinadas à observação e à verificação do funcionamento dos medidores de pressão.

Durante o período de experimentação em campo foi observada uma mudança climática na cidade de Campo Grande, que registrou temperaturas diárias abaixo da média típica para o período. Como os padróes de consumo variam em função do clima, optou-se por desprezar os dias (15 a 18 de abril de 2003) em que as temperaturas ficaram mais baixas que a média por não representar consumos típicos do sistema. Assim, determinou-se o período para análises entre os dias 19 e 23 de abril de 2003.

A primeira etapa para determinação dos padróes de consumo a serem considerados na calibração foi de avaliação das vazões abastecidas (entrada do setor) na rede de distribuição.

Observando-se os diversos cenários, pôde-se constatar a presença de manobras do registro de entrada do setor durante o período noturno. Segundo informações da própria companhia, essas manobras são realizadas de forma a minimizar as perdas (minimizar pressão) no sistema, durante o período noturno em que as pressóes são elevadas (consumo baixo). Optou-se por analisar os dados dos dias 20, 21 e 23, que apresentaram curvas de comportamentos similares para a vazão de consumo, supostamente na ausência de manobras. Os horários escolhidos para representar os padróes de consumo mínimo e máximo foram 3:00 horas e 11:00 horas, respectivamente, conforme ilustra a Figura 2.

\section{Simulações realizadas}

São descritas, a seguir, as etapas dos trabalhos desenvolvidos visando a calibração do modelo para obtenção dos parâmetros de vazamentos, além de eventuais manobras implementadas durante o período de coleta de dados. Primeiro, é demonstrada, por meio de um simples exemplo, a necessidade da consideração de um modelo hidráulico dirigido pela pressão para as análises hidráulicas.

\section{Utilização de modelo convencional (EPANET 2)}

A Tabela 1 apresenta os resultados das simulações hidráulicas efetuadas utilizando o modelo convencional (EPANET 2), o qual não admite vazamentos. Cabe salientar que, embora o software possua uma rotina para a simulação de vazamentos (emissores tipo orifício), Todini (2003) apresentou um estudo demonstrando que o emprego desses dispositivos no algoritmo (Método Gradiente de Todini \& Pilati, 1988) não resulta valores corretos nas simulações.

Uma comparação entre as pressões simuladas e observadas é possível, analisando-se os resultados apresentados na Tabela 1. A tabela apresenta também os desvios absolutos das pressões simuladas em relação às observadas para os dois padrôes considerados, evidenciando o elevado valor do erro absoluto total.

\section{Primeira tentativa: ajuste dos parâmetros do modelo de vazamentos sem considerar manobras no sistema}

A primeira tentativa, para determinação dos parâmetros do modelo pressão $\mathrm{x}$ vazamento por meio da calibração do modelo simplificado real, considerou duas válvulas redutoras de pressão atuando na rede, segundo informaçōes da companhia, localizadas próximas aos nós 14 e 130.

A primeira tentativa de calibração dos parâmetros de vazamento, considerado como um estudo preliminar, recebeu a denominação sem manobras. Esse termo denota a ausência de intervenções (manobras) sobre os registros do sistema ao longo do dia. Essa primeira tentativa de calibração visou principalmente utilizar os dados referentes às válvulas redutoras de pressão da própria companhia. A válvula localizada próxima ao nó 14 , segundo informações do departamento de operações da companhia de saneamento, reduz a pressão de jusante para $10 \mathrm{~m}$ e a válvula localizada próximo ao nó 130 reduz a pressão de jusante para $25 \mathrm{~m}$.

Por meio do conhecimento prévio da localização e ajuste dessas válvulas foi possível considerá-las no simulador hidráulico e proceder à calibração do modelo simplificado real. Os parâmetros de entrada do modelo de calibração, referentes ao módulo de otimização (AGs), foram: dimensão da população igual a 100, número de gerações igual a 500, seleção tipo Stochastic Remainder Sampling (SRS), recombinação aritmética com probabilidade 0,70 , mutação tipo Gaussiana com probabilidade 0,01 , escalonamento linear da função de aptidão (neste caso a função objetivo), e utilização de AG tipo geracional com taxa de $30 \%$ de elitismo.

A Tabela 2 apresenta os parâmetros ajustados para o modelo pressão $\mathrm{x}$ vazamento referentes ao primeiro estudo realizado (sem manobras). Inserindo-se os parâmetros estimados no simulador hidráulico iterativo foi possível obter as pressões nos nós da rede considerando vazamentos. Os resultados dessas simulaçōes, referentes às pressóes nos pontos

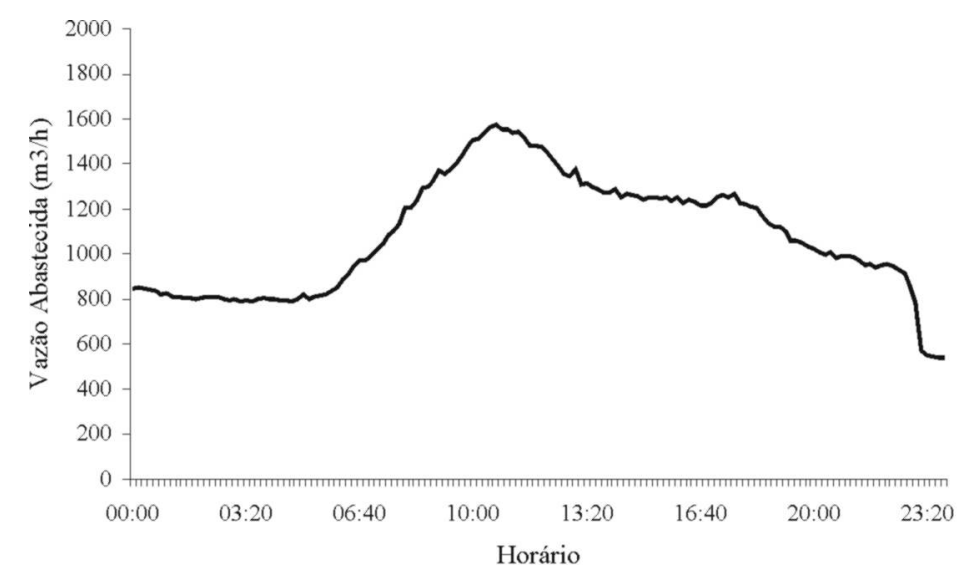

Figura 2 - Vazão abastecida (20/04/2003) 
Tabela I - Pressões nos nós monitorados (simuladas e observadas) - sem vazamentos e demanda variável com a pressão

\begin{tabular}{|c|c|c|c|c|c|c|c|}
\hline \multirow[t]{2}{*}{ Ponto } & \multirow[t]{2}{*}{ Nó } & \multicolumn{2}{|c|}{ Simulada $(\mathrm{m})$} & \multicolumn{2}{|c|}{ Observada (m) } & \multicolumn{2}{|c|}{ Erro absoluto (m) } \\
\hline & & Noturno & Diurno & Noturno & Diurno & Noturno & Diurno \\
\hline 1 & 128 & 83,6 & 82,2 & 73,9 & 50,6 & 9,7 & 31,6 \\
\hline 2 & 86 & 63,9 & 62,9 & 53,0 & 33,1 & 10,9 & 29,8 \\
\hline 3 & 106 & 80,1 & 78,0 & 65,1 & 37,6 & 15,0 & 40,4 \\
\hline 4 & 32 & 34,5 & 30,9 & 33,1 & 20,9 & 1,4 & 10,0 \\
\hline 5 & 14 & 34,3 & 34,2 & 28,8 & 28,6 & 5,5 & 5,6 \\
\hline 6 & 6 & 34,9 & 29,1 & 21,1 & 14,5 & 13,8 & 14,6 \\
\hline 7 & 25 & 55,5 & 53,4 & 23,2 & 15,3 & 32,3 & 38,1 \\
\hline 8 & 50 & 53,2 & 52,7 & 41,3 & 22,0 & 11,9 & 30,7 \\
\hline 9 & 122 & 82,3 & 80,9 & 72,0 & 46,0 & 10,3 & 34,9 \\
\hline \multirow[t]{3}{*}{10} & 115 & 87,7 & 85,2 & 75,0 & 45,0 & 12,7 & 40,2 \\
\hline & & & & \multicolumn{2}{|c|}{ Soma Parcial } & 123,4 & 275,9 \\
\hline & & & & \multicolumn{2}{|c|}{ Soma Total } & & 399,3 \\
\hline
\end{tabular}

Tabela 2 - Parâmetros do modelo pressão x vazamento referente ao modelo simplificado real

\begin{tabular}{ccccc}
\hline Setor & \multicolumn{2}{c}{$\theta\left(\mathrm{x} 10^{-7}\right)$} & \multicolumn{2}{c}{$\beta$} \\
& $\begin{array}{c}\text { Sem } \\
\text { manobras (1) }\end{array}$ & $\begin{array}{c}\text { Com } \\
\text { manobras (2) }\end{array}$ & $\begin{array}{c}\text { Sem } \\
\text { manobras (1) }\end{array}$ & $\begin{array}{c}\text { Com } \\
\text { manobras (2) }\end{array}$ \\
\hline 1 & 0,000 & 0,000 & 0,00 & 0,00 \\
2 & 0,000 & 0,294 & 0,10 & 1,07 \\
3 & 0,192 & 0,000 & 0,10 & 0,10 \\
4 & 0,398 & 0,039 & 1,16 & 0,58 \\
5 & 0,349 & 0,000 & 1,14 & 0,48 \\
\hline
\end{tabular}

Obs.: (1) Primeira tentativa

(2) Segunda tentativa

Tabela 3 - Pressões nos nós monitorados (observadas e simuladas) - com vazamentos e demanda variável com a pressão

\begin{tabular}{|c|c|c|c|c|c|c|}
\hline \multirow[t]{3}{*}{ Ponto } & \multirow{2}{*}{\multicolumn{2}{|c|}{ Observada (m) }} & \multicolumn{4}{|c|}{ Simulada $(\mathrm{m})$} \\
\hline & & & \multicolumn{2}{|c|}{ Sem manobras (1) } & \multicolumn{2}{|c|}{ Com manobras (2) } \\
\hline & Noturno & Diurno & Noturno & Diurno & Noturno & Diurno \\
\hline 1 & 73,9 & 50,6 & 85,2 & 78,6 & 74,2 & 48,8 \\
\hline 2 & 53,0 & 33,1 & 67,8 & 63,5 & 62,5 & 57,0 \\
\hline 3 & 65,1 & 37,6 & 79,7 & 69,6 & 70,9 & 41,4 \\
\hline 4 & 33,1 & 20,9 & 41,4 & 25,2 & 32,1 & 12,7 \\
\hline 5 & 28,8 & 28,6 & 37,9 & 37,7 & 32,1 & 30,1 \\
\hline 6 & 21,1 & 14,5 & 44,1 & 19,1 & 39,3 & 22,4 \\
\hline 7 & 23,2 & 15,3 & 61,1 & 51,7 & 51,5 & 36,2 \\
\hline 8 & 41,3 & 22,0 & 57,0 & 54,8 & 51,7 & 48,9 \\
\hline 9 & 72,0 & 46,0 & 83,5 & 76,2 & 72,9 & 46,8 \\
\hline 10 & 75,0 & 45,0 & 85,9 & 74,1 & 78,5 & 47,0 \\
\hline
\end{tabular}

Obs.: (1) Primeira tentativa

(2) Segunda tentativa monitorados, são agrupados na Tabela 3 .

Os desvios absolutos entre os dados observados e os simulados considerando vazamentos são apresentados na Tabela 4. Observa-se que a soma total dos valores absolutos desses desvios foi de 394,0 m o que resulta em uma melhoria irrelevante $(1,4 \%)$ quando comparado com o desvio das simulações sem considerar vazamentos (399,3 m).

\section{Segunda tentativa: ajuste dos parâmetros do modelo de vazamentos e das manobras (valores médios para os dois padrões)}

Uma segunda etapa do estudo de calibração foi desenvolvida levando-se em consideração a eventual existência de manobras sobre os registros da rede. As localizaçōes das manobras foram obtidas junto à companhia de saneamento e são ilustradas na Figura 3. Uma das principais dificuldades em representar operaçôes (manobras de registros) nas simulaçōes hidráulicas é identificar as aberturas das válvulas resultantes das manobras (coeficiente de perda de carga localizada número de voltas no caso de registros manuais). Assim, os ajustes das manobras foram considerados como variáveis de decisão do problema de calibração, em conjunto com os parâmetros do modelo pressão $\mathrm{x}$ vazamento.

A Tabela 2 também apresenta os valores dos parâmetros estimados (coeficiente e expoente de vazamentos) para o modelo pressão $\mathrm{x}$ vazamento para o estudo denominado com manobras. Nesse estudo, os parâmetros de vazamentos e os ajustes das manobras são valores médios representativos dos dois padróes de consumo considerados, ou seja, o coeficiente ou expoente de perda de um setor e o coeficiente de perda de carga localizada de uma válvula possuem os mesmos valores tanto no padrão diurno quanto noturno. A Tabela 3 apresenta as pressões simuladas para esse estudo.

$\mathrm{Na}$ Tabela 4 são apresentados os desvios absolutos para o segundo estudo de calibração. Observa-se que a soma do desvio total considerando os dois padrōes de consumo é igual a 178,9 m. Comparando esse valor $(178,9 \mathrm{~m})$ com o desvio $(399,3 \mathrm{~m})$ referente à simulação em que não foram considerados vazamentos (Tabela 1), observa-se uma melhoria global de $55,2 \%$. Entretanto, quando as pressões são analisadas aos pares, para cada padrão de consumo, os resultados apre- 
Tabela 4 - Erro absoluto referente às pressões simuladas - com vazamentos e demanda variável com a pressão

\begin{tabular}{ccccc}
\hline Ponto & \multicolumn{4}{c}{ Erro absoluto (m) } \\
& Sem manobras (1) & Com manobras (2) \\
& Noturno & Diurno & Noturno & Diurno \\
\hline 1 & 11,3 & 28,0 & 0,3 & 1,8 \\
2 & 14,8 & 30,4 & 9,5 & 23,9 \\
3 & 14,6 & 32,0 & 5,8 & 3,8 \\
4 & 8,3 & 4,3 & 1,0 & 8,2 \\
5 & 9,1 & 9,1 & 3,3 & 1,5 \\
6 & 23,0 & 4,6 & 18,2 & 7,9 \\
7 & 37,9 & 36,4 & 28,3 & 20,9 \\
8 & 15,7 & 32,8 & 10,4 & 26,9 \\
9 & 11,5 & 30,2 & 0,9 & 0,8 \\
10 & 10,9 & 29,1 & 3,5 & 2,0 \\
Soma parcial & 157,1 & 236,9 & 81,2 & 97,7 \\
Soma total & & 394,0 & & 178,9 \\
\hline
\end{tabular}

Obs.: (1) Primeira Tentativa (2) Segunda Tentativa

sentam diferenças significativas. Uma possível razão para as discrepâncias dessas pressōes pode estar relacionada às manobras diferenciadas para cada padrão de consumo. No Brasil, manobras noturnas são realizadas em grande parte dos sistemas de distribuição de água, como operações rotineiras realizadas com o objetivo de reduzir a pressão noturna e, assim, minimizar as perdas por vazamento.

\section{Terceira tentativa: ajuste dos parâmetros do modelo de vazamentos e das manobras (valores distintos para cada padrão)}

Analisando-se as pressões obtidas por meio da calibração para as duas situaçôes (sem e com manobras) percebe-se que, no sistema RF-1 ocorrem operações (manobras em registros) distintas nos diferentes períodos do dia (noturno e diurno). Dessa forma, realizou-se um outro estudo (terceira tentativa) de calibração com objetivo de identificar manobras e parâmetros de vazamentos distintos para cada padrão de consumo considerado.

As Tabelas 5 e 6 apresentam os valores dos parâmetros ajustados para o modelo pressão $\mathrm{x}$ vazamento referente ao terceiro estudo de calibração (manobras e parâmetros distintos para os diferentes padrōes considerados) e os coeficientes de perda de carga localizada ajustados, respectivamente, para cada padrão de consumo considerado. Os valores de pressão, referentes aos pontos monitorados e os desvios absolutos são agrupados na Tabela 7. Observa-se que a soma total desses desvios foi de $98,0 \mathrm{~m}$ que implica em uma melhoria de $75,5 \%$ quando comparada com o desvio absoluto total das simulaçôes sem considerar vazamentos (399,3 m). Nota-se também que, no período noturno apenas dois pontos de monitoramento (6 e 7) não apresentaram bons ajustes.

Para o período diurno os pontos $4 \mathrm{e}$ 7 não apresentaram bons ajustes. É possível observar que todos os pontos que não apresentaram bons ajustes pertencem ao setor 2 (Figura 1). Um resultado interessante que merece ser destacado é que o procedimento de calibração permitiu identificar a regra operacional adotada pela companhia no setor RF-1 para diferentes períodos do dia. Isso pode ser verificado analisando-se os ajustes das manobras na Tabela 6. Observa-se que durante o período noturno os registros 1 e 4 (Figura 3) estão quase que fechados, já os registros 1 e 2 encontram-se parcialmente fechados. Por meio desses resultados é possível afirmar a existência de manobras diferenciadas para os dois padrões de consumo considerados.

\section{Quarta tentativa: ajuste dos parâmetros do modelo de vazamentos (valores médios para os dois padrões) considerando manobras distintas}

Todos os estudos de calibração realizados até o momento foram desenvolvidos como etapas preliminares de investigação. Como o modelo de calibração adotado é baseado em uma técnica de busca estocástica (AG), várias simulações, utilizando populaçōes iniciais distintas, são necessárias para estabelecer confiança nos resultados obtidos. Um quarto estudo teve como objetivo determinar coeficientes de ajuste médios para cada manobra (a partir de cinco populaçôes iniciais distintas), em um primeiro passo, e parâmetros de vazamentos globais, no segundo passo (dez populaçóes iniciais distintas). Cada simulação (a partir de uma população inicial) foi processada em aproximadamente 50 minutos. Os valores médios das manobras são referentes a cada padrão de consumo. Depois de conhecidas as manobras, as mesmas foram inseridas no processo de calibração para obter, então, os parâmetros globais (considerando um valor para os dois padrões) para o modelo pressão x vazamento. Os valores ajustados das manobras são apresentados na Tabela 8 e as médias dos parâmetros globais estimados são apresentadas na Tabela 9, que também apresenta o cálculo do coeficiente de variação para as dez simulações realizadas. O setor 5 apresentou maior variação, em cada simulação, tanto para o coeficiente de vazamento $(\theta)$ quanto para o expoente de vazamento $(\beta)$.

Os valores de pressóes referentes aos pontos monitorados e os respectivos desvios absolutos são agrupados na Tabela 10. O desvio total encontrado na simulação resultou em uma melhoria de $76,3 \%$ quando comparado com o desvio das simulaçôes sem considerar vazamentos (399,3 m). Com base nos desvios totais da simulação, a utilização de parâmetros de vazamentos globais apresenta uma ligeira melhoria quando comparado com os desvios do estudo que identificou parâmetros de vazamentos distintos 


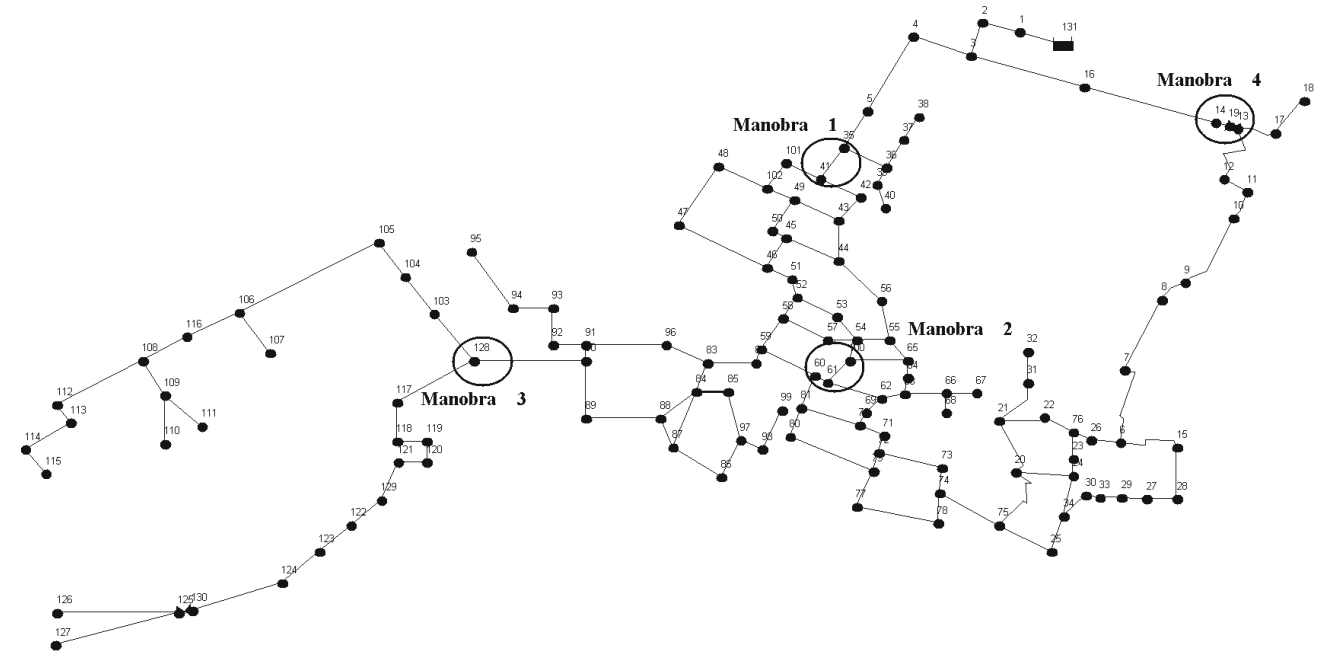

Figura 3 - Localização dos pontos de manobra realizadas na rede

Tabela 5 - Parâmetros do modelo pressão x vazamento para diferentes padrões de consumo

\begin{tabular}{ccccc}
\hline Setor & \multicolumn{2}{c}{$\theta\left(\mathrm{x} 10^{-7}\right)$} & \multicolumn{2}{c}{$\beta$} \\
& Noturno & Diurno & Noturno & Diurno \\
\hline 1 & 0,00 & 0,00 & 0,00 & 0,00 \\
2 & 0,88 & 0,00 & 1,16 & 0,32 \\
3 & 0,72 & 0,66 & 0,10 & 1,14 \\
4 & 0,37 & 0,42 & 0,47 & 1,17 \\
5 & 0,00 & 0,44 & 0,10 & 0,90 \\
\hline
\end{tabular}

Tabela 6 - Ajuste das manobras para os diferentes padrões de consumo

\begin{tabular}{ccccc}
\hline Manobra & \multicolumn{4}{c}{ Coeficiente de perda de carga localizada (K) } \\
& 1 & 2 & 3 & 4 \\
\hline Diurno & 994 & 10 & 32 & 132 \\
Noturno & 1187 & 688 & 367 & 1178 \\
\hline
\end{tabular}

Tabela 7 - Pressões nos nós monitorados (observadas e simuladas considerando manobras e parâmetros de vazamento diferenciados para cada padrão de consumo)

\begin{tabular}{|c|c|c|c|c|c|c|}
\hline \multirow[t]{2}{*}{ Ponto } & \multicolumn{2}{|c|}{ Observada (m) } & \multicolumn{2}{|c|}{ Simulada $(\mathrm{m})$} & \multicolumn{2}{|c|}{ Erro absoluto (m) } \\
\hline & Noturno & Diurno & Noturno & Diurno & Noturno & Diurno \\
\hline 1 & 73,9 & 50,6 & 72,0 & 47,4 & 1,9 & 3,2 \\
\hline 2 & 53,0 & 33,1 & 54,4 & 30,6 & 1,4 & 2,5 \\
\hline 3 & 65,1 & 37,6 & 69,0 & 41,0 & 3,9 & 3,4 \\
\hline 4 & 33,1 & 20,9 & 26,9 & 4,4 & 6,2 & 16,5 \\
\hline 5 & 28,8 & 28,6 & 32,0 & 29,8 & 3,2 & 1,2 \\
\hline 6 & 21,1 & 14,5 & 34,3 & 15,4 & 13,2 & 0,9 \\
\hline 7 & 23,2 & 15,3 & 46,4 & 25,2 & 23,2 & 9,9 \\
\hline 8 & 41,3 & 22,0 & 43,3 & 21,9 & 2,0 & 0,1 \\
\hline 9 & 72,0 & 46,0 & 70,8 & 45,7 & 1,2 & 0,3 \\
\hline \multirow[t]{3}{*}{10} & 75,0 & 45,0 & 76,7 & 47,1 & 1,7 & 2,1 \\
\hline & & & \multicolumn{2}{|c|}{ Soma parcial } & 57,9 & 40,1 \\
\hline & & & \multicolumn{2}{|c|}{ Soma total } & & 98,0 \\
\hline
\end{tabular}


Avaliação de perdas físicas de rede de abastecimento de água

Tabela 8 - Manobras ajustadas considerando padrões de consumo distintos

Coeficiente de perda de carga

localizada (K) do EPANET 2

\begin{tabular}{cccccc} 
& Simulação & 1 & 2 & 3 & 4 \\
\hline Diurno & 1 & 994 & 10 & 32 & 132 \\
& 2 & 1004 & 10 & 10 & 196 \\
& 3 & 1037 & 127 & 160 & 36 \\
\multirow{5}{*}{ Noturno } & 4 & 1032 & 103 & 10 & 83 \\
& 5 & 1009 & 157 & 57 & 10 \\
& 2 & 1187 & 688 & 367 & 1178 \\
& 3 & 1170 & 767 & 406 & 1167 \\
& 4 & 1199 & 570 & 310 & 1191 \\
& 5 & 1195 & 783 & 500 & 1160 \\
& & 1015 & 81 & 54 & 91 \\
& & 1184 & 703 & 398 & 1167 \\
\hline
\end{tabular}

Tabela 9 - Parâmetros globais do modelo de vazamentos

\begin{tabular}{|c|c|c|c|c|}
\hline \multirow[t]{2}{*}{ Setor } & \multicolumn{2}{|c|}{$\theta\left(\mathrm{x} 10^{-7}\right)$} & \multicolumn{2}{|c|}{$\beta$} \\
\hline & Média & CV & Média & $\mathrm{CV}$ \\
\hline 1 & 0,00 & - & 0,00 & - \\
\hline 2 & 0,83 & 0,08 & 1,17 & 0,02 \\
\hline
\end{tabular}

Tabela 10 - Pressões simuladas considerando parâmetros de vazamentos globais

\begin{tabular}{|c|c|c|c|c|c|}
\hline & Ponto & Nó & $\begin{array}{l}\text { Simulada } \\
(\mathrm{m})\end{array}$ & $\begin{array}{l}\text { Observada } \\
(\mathrm{m})\end{array}$ & $\begin{array}{c}\text { Erro absoluto } \\
(\mathrm{m})\end{array}$ \\
\hline \multirow[t]{11}{*}{ Noturno } & 1 & 128 & 70,6 & 73,9 & 3,27 \\
\hline & 2 & 86 & 54,3 & 53,0 & 1,27 \\
\hline & 3 & 106 & 66,3 & 65,1 & 1,22 \\
\hline & 4 & 32 & 26,9 & 33,1 & 6,24 \\
\hline & 5 & 14 & 32,0 & 28,8 & 3,24 \\
\hline & 6 & 6 & 34,4 & 21,1 & 13,30 \\
\hline & 7 & 25 & 45,9 & 23,2 & 22,74 \\
\hline & 8 & 50 & 43,2 & 41,3 & 1,86 \\
\hline & 9 & 122 & 69,4 & 72,0 & 2,57 \\
\hline & 10 & 115 & 73,3 & 75,0 & 1,66 \\
\hline & & & & Soma Parcial & 57,38 \\
\hline \multirow[t]{12}{*}{ Diurno } & 1 & 128 & 48,8 & 50,6 & 1,82 \\
\hline & 2 & 86 & 33,6 & 33,1 & 0,48 \\
\hline & 3 & 106 & 40,2 & 37,6 & 2,62 \\
\hline & 4 & 32 & 3,9 & 20,9 & 16,98 \\
\hline & 5 & 14 & 29,7 & 28,6 & 1,10 \\
\hline & 6 & 6 & 14,5 & 14,5 & 0,03 \\
\hline & 7 & 25 & 25,9 & 15,3 & 10,64 \\
\hline & 8 & 50 & 24,7 & 22,0 & 2,66 \\
\hline & 9 & 122 & 46,9 & 46,0 & 0,89 \\
\hline & 10 & 115 & 45,2 & 45,0 & 0,21 \\
\hline & & & & Soma parcial & 37,42 \\
\hline & & & & Soma total & 94,80 \\
\hline
\end{tabular}


A Tabela 11 apresenta as vazões abastecidas ajustadas e a vazão abastecida real para os diferentes padrôes de consumo considerados. Observa-se que o ajuste do balanço de massa é muito eficiente, verificado pelos baixos valores dos desvios relativos apresentados.

Pode-se observar na Tabela 10 que, para o período noturno, os pontos 4, $6 \mathrm{e}$ 7 apresentam os piores ajustes. No período diurno, os piores resultados são encontrados para os pontos 4 e 7 . Esses pontos (4, 6 e 7$)$ pertencem ao setor 2 , conforme indicação da Figura 1. Algumas fontes de incerteza estão associadas a esses pontos, merecendo ser mencionadas. Existe uma indefinição na estimativa da demanda referente ao ponto 4 . Os dados de demanda estimados para efeito de desenvolvimento do presente trabalho foram obtidos de um estudo de demanda realizado em 1996 pela companhia. Naquela época, toda área próxima ao ponto 4 era abastecida pelo sistema RF-1. Entretanto, durante o levantamento de campo realizado na época da coleta de dados para este trabalho, observou-se que um sistema isolado, contendo uma bomba de sucção de água subterrânea, estava abastecendo parte da área de influência do ponto 4 . Nota-se, portanto, que as demandas reais, referentes ao ano de 2003, deveriam ser menores que as de 1996. Observa-se, então, na Tabela 10, o motivo pelo qual as pressóes observadas são maiores do que as pressões simuladas, pois há menos consumo do que o estimado para aquele ponto.

Quanto ao ponto 6, no período diurno, houve um ótimo ajuste em relação à pressão observada. Por outro lado, no período noturno, a pressão observada apresentou-se menor que a simulada. Conclui-se que alguma operação é realizada no período noturno para aliviar a pressão do ponto 6 ou que existe alguma singularidade desconhecida pela companhia naquele setor. Foi levantada a hipótese de que outras manobras estariam sendo realizadas no período noturno internamente ao setor 2 , afetando, dessa forma, a pressão no ponto 6 . No entanto, segundo a companhia de saneamento as manobras só ocorrem nos locais assinalados na Figura 3.

Em relação ao ponto 7, os desvios apresentados representam alívios de pressão tanto no período diurno quanto no período noturno. Segundo informações da companhia, isso acontece porque recentemente foi construída uma derivação, próxima a esse ponto, para atender
Tabela I I - Vazões abastecidas simuladas e observadas considerando parâmetros de vazamentos globais

\begin{tabular}{ccccc}
\hline Padrão & Trecho & \multicolumn{3}{c}{ Vazão abastecida (L/s) } \\
& & Simulada & Observada & Erro relativo (\%) \\
\hline Noturno & 118 & 247,0 & 246,94 & 0,03 \\
Diurno & 118 & 457,4 & 457,50 & $-0,02$ \\
\hline
\end{tabular}

um bairro vizinho e que não consta do cadastro.

Outras possíveis fontes de incerteza podem ser mencionadas tais como, por exemplo, os erros de leitura dos equipamentos (medidores de pressão e vazão), a localização inadequada dos pontos de monitoramento de pressão devido a cadastros desatualizados (estar monitorando um sistema isolado ao invés do sistema RF-1), erros nas estimativas de demandas nodais, coeficientes de rugosidade das tubulações e singularidades (válvulas) desconhecidas.

Pode-se considerar que os resultados obtidos pelo modelo calibrado são animadores, principalmente se forem consideradas as incertezas relativas ao setor 2 e, também, que a fase de identificação e reparo de vazamentos grosseiros, que deveria preceder a coleta de dados, foi inviável.

Utilizando os parâmetros estimados do modelo pressão x vazamento (Tabela 12), foram realizadas quatro simulaçóes para os dois padrôes de consumo adotados (diurno e noturno). Foram também estimadas as perdas físicas (vazamentos - Tabelas 13 e 14) do setor RF-1 para os dois períodos considerados (diurno e noturno) através do simulador hidráulico iterativo.
Observa-se na Tabela 13 que, se não houvesse manobras na rede durante o período diurno, a perda física estimada para o sistema seria de 64,4 L/s. Considerando a vazão abastecida para esse período de 457,5 L/s, obtém-se o índice de vazamentos de $14,1 \%$. Considerando manobras, para o mesmo período, o índice de vazamentos apresenta-se em torno de $8,2 \%$. rem realizadas manobras, as perdas por vazamento giram em torno de $31,1 \%$, considerando uma vazão abastecida de $246,94 \mathrm{~L} / \mathrm{s}$. Caso sejam realizadas manobras, as perdas por vazamento passa a ser de $26,4 \%$.

No presente trabalho, os valores obtidos para o expoente de vazamentos (Tabela 11) se apresentaram no intervalo entre 0,0 e 1,20. Reis et al. (2004) avaliaram parâmetros do modelo de vazamentos para setores da cidade de São CarlosSP por meio de testes noturnos de vazamentos. Foram empregados dois métodos para determinação dos valores de $\beta$ do modelo de vazamentos. O primeiro método, baseado em análises de regressão, identificou valores para $\beta$ entre 1,15 e 1,18 . O segundo método, baseado em um procedimento inverso, identificou
Para o período noturno, se não fo-

Tabela 12 - Parâmetros do modelo de vazamentos

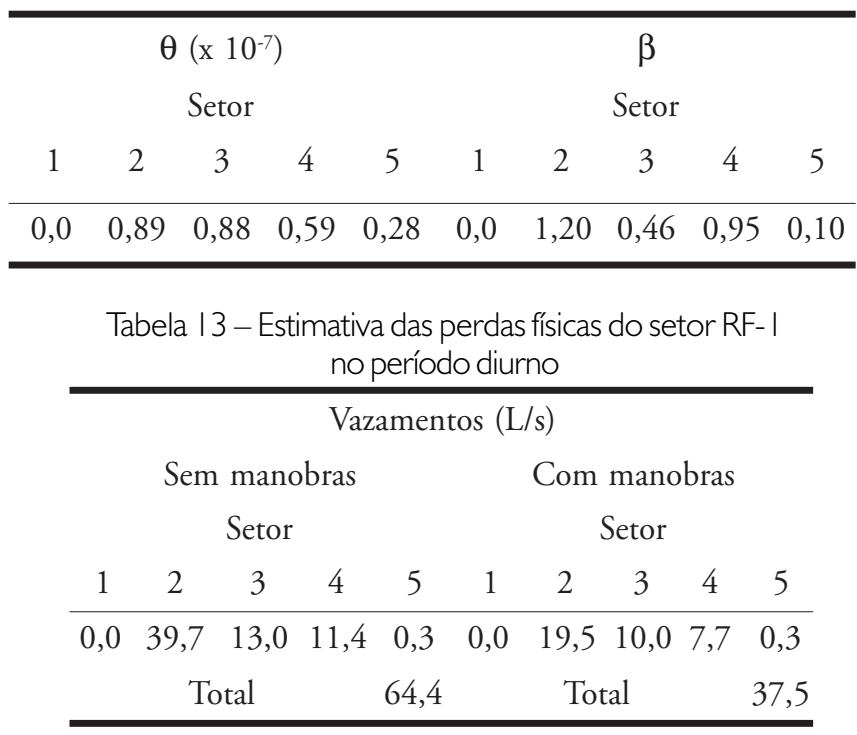


Tabela 14 - Estimativa das perdas físicas do setor RF- | no período noturno

\begin{tabular}{ccccccccccc}
\hline \multicolumn{1}{c}{ Vazamentos $(\mathrm{L} / \mathrm{s})$} \\
\multicolumn{4}{c}{$\begin{array}{c}\text { Sem manobras } \\
\text { Setor }\end{array}$} & \multicolumn{1}{c}{ Com manobras } \\
\hline 1 & 2 & 3 & 4 & 5 & 1 & 2 & 3 & 4 & 5 \\
\hline 0,0 & 50,1 & 13,4 & 13,0 & 0,3 & 0,0 & 40,9 & 12,5 & 11,4 & 0,3 \\
& & Total & & 76,8 & & Total & & 65,1 \\
\hline
\end{tabular}

valores de $\beta$ entre 0,49 e 1,1 . Com base nessas investigações pode-se afirmar que cada sistema possui seus parâmetros característicos, reafirmando a necessidade de um procedimento de calibração.

\section{CONCLUSÕES}

Um estudo das perdas físicas de um setor da rede de abastecimento de água da cidade de Campo Grande-MS foi reportado no presente trabalho. Para tanto, foi utilizado um modelo de calibração apoiado em um procedimento iterativo de avaliação hidráulica que considera vazamentos e demandas dirigidas pela pressão. O algoritmo para análise hidráulica utiliza o simulador hidráulico EPANET 2 como módulo auxiliar. Eliminou-se, assim, a necessidade de intervenção direta sobre o código fonte do software, embora tal procedimento eleve o tempo de processamento computacional das simulaçôes.

Diferentes padrôes de demanda são considerados nas simulaçôes e as perdas físicas são determinadas considerando as operaçóes realizadas durante a campanha de campo, necessária para a coleta dos dados de pressão em alguns nós da rede e da vazão abastecida pelos reservatórios.

As investigaçóes revelaram a necessidade de um controle mais efetivo sobre o setor 2 do sistema RF-1, como determinação das demandas nodais, identificação das regiōes realmente abastecidas pelo sistema, levantamento e reparo de possíveis vazamentos localizados com o uso de equipamentos acústicos, localização de possíveis componentes hidráulicos não cadastrados, determinação das rugosidades das tubulações, além de identificação de possíveis derivações para outros sistemas.

Considerando a complexidade do sistema avaliado neste trabalho (atendimento de cerca de 100.000 habitantes), os resultados apresentados foram muito satisfatórios e evidenciam a necessidade das companhias de saneamento em utilizar ferramentas computacionais que representem as condiçóes de campo com um nível de realismo maior.

\section{AGRADECIMENTOS}

À Coordenadoria de Aperfeiçoamento de Pessoal de Nível Superior (CAPES), pela bolsa de estudos concedi$\mathrm{da}$ aos dois primeiros autores, ao $\mathrm{CNPq}$, pelo apoio financeiro concedido ao Projeto (CT-HIDRO 01/2001) "Instrumentos do Uso Racional e Otimizado da Água em Meio Urbano", do qual este trabalho é parte integrante, à Companhia de Saneamento Águas Guariroba S.A., pelo apoio logístico e técnico nas investigações de campo, ao Técnico Nelson Mota Vieira, pelo auxílio na instrumentação de campo, e aos revisores anônimos pelas correçōes e sugestões apresentadas.

\section{REFERÊNCIAS}

REIS, L. F. R. et al. Avaliação dos Parâmetros do Modelo de Vazamentos para Setores de Rede da Cidade de São Carlos - SP. Revista Brasileira de Recursos Hídricos, v. 9, n. 1, p. 85-96, Jan/Mar 2004.

ROSSMAN, L. A. EPANET 2 users manual. U.S. EnvironmentalProtection Agency, Cincinnati, Ohio, 2000.

SANDIM, M. P. et al. Plano Diretor do Sistema de Abastecimento de Agua de Campo Grande (2000 - 2030), 2002.

SOARES, A. K. Calibração de Modelos de Redes de Distribuição de Água para Abastecimento Considerando Vazamentos e Demandas Dirigidas pela Pressão. São Carlos, Dissertação (Mestrado). Escola de Engenharia de São Carlos, Universidade de São Paulo. 152 p. 2003

TODINI, E. A More Realistic Approach to the "Extended Period Simulation" of Water Distribution Networks. In: ADVANCES IN WATER SUPPLY MANAGEMENT. MAKSIMOVIC, C.; BUTLER, D.; MEMON, F. A. (eds.), Swets \& Zeitlinger, Lisse, The
Netherlands, 2003.

TODINI, E.; PILATI, S. A Gradient Algorithm for the Analysis of Pipe Networks. In: COMPUTER APPLICATIONS IN WATER SUPPLY - SYSTEM ANALYSIS AND SIMULATION. COULBECK, B.; ORR, C. H. (eds.), vol. 1, p. 1-20, 1988.

TUCCIARELLI, T.; CRIMINISI, A.; TERMINI, D. Leak Analysis in Pipeline Systems by Means of Optimal Valve Regulation. Journal of Hydraulic Engineering, v. 125, n. 3, p. 277-285, Mar 1999.

WALL, M. GAlib: A $C++$ Library of Genetic Algorithm Components. Mechanical Engineering

Endereço para correspondência:

Alexandre Kepler Soares

Dep. de Hidráulica e Saneamento EESC/USP

Av. Trabalhador São-Carlense, 400

Caixa Postal 359

I3566-590 São Carlos - SP - Brasil

Tel.: (I6) 3373-9552

Fax: (16) 3373-9550

E-mail:aksoares@sc.usp.br 